the evoked potential in acute schizophrenics during a test of sustained attention. Biol Psychiatry 15:9-20.

Pfefferbaum A, Wenegrat BG, Ford JM, Roth WT, Kopell BS (1984): Clinical application of the P3 component of event-related potentials. II. Dementia, depression and schizophrenia. Electroencephalogr Clin Neurophysiol 59:104-124.
Pritchard WS (1986): Cognitive event-related potentials in schizophrenics. Psychol Bull 100:43-66.

Walker E, Shaye J (1982): Familial schizophrenia: A predictor of neuromotor and attentional abnormalities in schizophrenia. Arch Gen Psychiatry 39:1153-1156.

\title{
Chronic Treatment with Lithium Produces Supersensitivity to Nicotine
}

\section{Steven C. Dilsaver and M. Hariharan}

\section{Introduction}

Dilsaver et al. (1988) reported that amitriptyline produces supersensitivity of a nicotinic mechanism involved in the regulation of core temperature. We now present data indicating that chronically administered lithium ion also has this effect. We will discuss the potential theoretical significance of this finding and review other data indicating that treatments for depression alter sensitivity to nicotine.

\section{Methods}

The dependent variable in the experiments reported here was change in core temperature in

From the Department of Psychiatry, Ohio State University, Columbus, OH (S.C.D.), and the Clinical Laboratory, Mental Health Research Institute, Department of Psychiatry, University of Michigan, Ann Atbor, MI (M.H.).

Supported by Physician Scientist Career Development Award (Muscarinic Receptor Abnormalities in Affective Illness) MH0055032 and NIH 2507RR05383-25.

Address reprint requests to Dr. S. C. Dilsaver, Department of Psychiatry, Ohio State University College of Medicine, 473 West 12th Avenue, Columbus, $\mathrm{OH} 43201-1228$.

Received August 20, 1987; revised June 21, 1988. response to nicotine (base), 0.40 or $1.0 \mathrm{mg} / \mathrm{kg}$ intraperitoneally (ip) in adult male SpragueDawley rats housed individually. Core temperature was telemetrically measured with the model VM Mini-Mitter (Mini-Mitter Co., Sun River, OR). These instruments, which emit radio waves at a rate directly proportional to temperature, are implanted into the peritoneal cavity. The rats were allowed 5 days to recover prior to starting an experiment. A digital frequency counter (model 5001 Universal counter-timer; Global Specialties, New Haven, CT) connected to an AM receiver was used to determine the emission rates of each Mini-Mitter. This measurement was converted to temperature in degrees Celsius $\left({ }^{\circ} \mathrm{C}\right)$ using a linear regression equation derived by measuring the emission profile of each instrument in a temperature-controlled water bath (Dilsaver et al. 1989). The principles governing the use of the Mini-Mitter in psychopharmacological research is described in detail elsewhere (Dilsaver and Alessi 1988). Each of the three experiments below required the measurement of temperature prior to the injection of saline or nicotine (at $t=0$ ) and every $10 \mathrm{~min}$ 
thereafter for $120 \mathrm{~min}$. The mean thermic response relative to $t=0$ entered into the statistical analyses. This was calculated by averaging the change in core temperature relative to $t=$ $0,10,20,30 \ldots, 120 \mathrm{~min}$ after the injection of saline or nicotine. Mean maximum thermic response to saline and nicotine are listed for completeness and descriptive purposes only. We previously reported that these values are relatively useless for statistical analysis (Dilsaver and Alessi 1988).

Nicotine (base) was purchased from Sigma Chemical Company (St. Louis, MO). Lithium chloride $(\mathrm{LiCl})$ was obtained from Fisher Scientific (Pittsburgh, PA). Doses of nicotine and lithium refer to the base and salt forms, respectively.

Lithium levels were measured by atomic absorption spectrophotometry. This assay has intra- and interassay coefficients of variation of $4.2 \%$ and $5.0 \%$, respectively. Challenges were started between 7:00 and 9:00 AM and 9:00 and 10:00 AM in Experiments 1 and 2, respectively. Each subject was challenged with saline $(1 \mathrm{ml} / \mathrm{kg})$ prior to beginning treatment with lithium. The saline challenge provides a baseline against which we could compare the thermic response to nicotine. The effect of routine handling and saline injection is hyperthermia (Dilsaver and Majchrzak 1989). The animals were then challenged (on a separate day) with nicotine (base), 1.0 $\mathrm{mg} / \mathrm{kg}$ ip in Experiment 1 and $0.4 \mathrm{mg} / \mathrm{kg}$ ip in Experiment 2. Treatment with $\mathrm{LiCl}$ followed the baseline challenge with nicotine. The subjects ( $\mathrm{n}=8$ ) were treated with $\mathrm{LiCl}, 160 \mathrm{mg} / \mathrm{kg} \mathrm{ip}$, at 9:00 AM and 5:00 PM for 14 days in Experiment 1. The last dose of $\mathrm{LiCl}$ was given $14 \mathrm{hr}$ prior to the third and last challenge with nicotine. $\mathrm{LiCl}, 120 \mathrm{mg} / \mathrm{kg}$ ip, was given at $10: 30$ AM and 10:30 PM in Experiment $2(n=6)$ for 6 days. The last dose was given $10.5 \mathrm{hr}$ prior to the second nicotine challenge. Blood was drawn by cardiac puncture for measurement of the 16hr trough lithium level in Experiment 1. Trunk blood was collected for measurement of the plasma lithium level $12 \mathrm{hr}$ after the last dose in Experiment 2.
A control experiment was designed to assess the effects of chronic saline injections on the thermic responsiveness of rats to nicotine. MiniMitters were implanted into 11 adult male Sprague-Dawley rats. The animals were allowed 5 days to recover prior to being challenged with saline $(1.0 \mathrm{ml} / \mathrm{kg})$. The following day the rats were challenged with nicotine (base), $1.0 \mathrm{mg} / \mathrm{kg}$. Following this challenge, each animal received saline, $1 \mathrm{ml} / \mathrm{kg}$ ip, at 9:00 $\mathrm{AM}$ and 5:00 PM for 14 consecutive days. The thermic response to nicotine was reassessed after 7 and 14 days of treatment with saline. Saline and nicotine challenges began at 9:00 AM. The second and third nicotine challenges occurred on the 8th (i.e., after 7 days of treatment) and 15th (after 14 full days of treatment) days of the experiment, respectively. Challenges occurred $16 \mathrm{hr}$ after the preceding injection of saline. The first injection of saline on the 8th day followed the completion of temperature measurements at 11:00 AM.

Data were analyzed by one-way Analysis of Variance (ANOVA) for repeated measures, followed by Student's paired $t$-tests in Experiments 1 and 3. Data were analyzed by the Student's paired $t$-test in Experiment 2. Analyses were two-tailed. Measures of variance refer to the standard error of the mean (SEM).

\section{Results}

\section{Experiment 1}

The mean mass of the animals used in this experiment was $257.5 \pm 2.4 \mathrm{~g}$. Mean core temperature at rest prior to challenge with saline was $37.4 \pm 0.22^{\circ} \mathrm{C}$.

The mean peak effect of handling the animals and injecting saline was $+0.95 \pm 0.18^{\circ} \mathrm{C}$. The mean thermic response to saline was $+0.73 \pm$ $0.16^{\circ} \mathrm{C}$. The mean peak thermic responses to nicotine before and after 1 and 2 weeks of treatment were $-1.45 \pm 0.30^{\circ} \mathrm{C},-1.90 \pm 0.24^{\circ} \mathrm{C}$, and $-2.2 \pm 0.17^{\circ} \mathrm{C}$, respectively. The subjects exhibited mean thermic responses to nicotine at baseline and after 1 and 2 weeks of treatment with lithium of $-0.60 \pm 0.24^{\circ} \mathrm{C},-0.99 \pm$ 
$0.15^{\circ} \mathrm{C}$, and $-1.41 \pm 0.17^{\circ} \mathrm{C}$, respectively The mean thermic response to saline differed from the initial response to nicotine $(p<0.004$, $t=4.38$, df $=7$ ). A one-way ANOVA for repeated measures suggested that the responses to nicotine differed across time ( $\mathrm{df}=2 / 21, f$ $=4.6, p<0.025$ ). The thermic response to nicotine differed from baseline following 2 weeks of treatment $(p<0.03, t=2.76$, df $=7)$, but not after 1 week.

The mean plasma lithium concentration 16 $\mathrm{hr}$ after the last dose was $0.69 \pm 0.05 \mathrm{meq} / \mathrm{liter}$.

\section{Experiment 2}

The mean mass of the rats used in this experiment was $302.8 \pm 7.4 \mathrm{~g}$. Mean core temperature at rest prior to challenge with saline was $37.9 \pm 0.44^{\circ} \mathrm{C}$.

The mean maximum effect of handling the animals and injecting saline was $+1.00 \pm$ $0.26^{\circ} \mathrm{C}$. The mean thermic response to saline was $+0.80 \pm 0.25^{\circ} \mathrm{C}$. The mean maximum thermic response to nicotine was $-0.92 \pm$ $0.21^{\circ} \mathrm{C}$ at baseline. The mean thermic response to nicotine at baseline was $-0.39 \pm 0.21^{\circ} \mathrm{C}$. This differed from the response to saline at the 0.04 level $(t=2.87$, df $=5)$. The sample exhibited a mean maximum hypothermic response to nicotine after 1 week of treatment with lithium of $-2.27 \pm 0.29^{\circ} \mathrm{C}$. The sample exhibited a mean thermic response to nicotine of $-1.35 \pm 0.14^{\circ} \mathrm{C}$ following 6 days of treatment with lithium. This differed from the response at baseline ( $p<0.03, t=3.15$, $\mathrm{df}=5$ ).

The mean 12-hr trough lithium concentration was $1.44 \pm 0.28 \mathrm{meq} / \mathrm{liter}$.

\section{Experiment 3}

The mean mass of the sample used in this experiment was $267.3 \pm 2.4 \mathrm{~g}$. The mean core temperature of the sample prior to challenge with saline was $37.1 \pm 0.05^{\circ} \mathrm{C}$.

The mean maximum thermic response to handling the animals and injecting saline injection was $+0.84 \pm 0.07^{\circ} \mathrm{C}$. The mean thermic response to saline was $+0.72 \pm 0.05^{\circ} \mathrm{C}$. The sample exhibited mean maximum thermic responses to nicotine of $-1.2 \pm 0.09^{\circ} \mathrm{C},-0.92$ $\pm 0.09^{\circ} \mathrm{C}$, and $-0.73 \pm 0.09^{\circ} \mathrm{C}$ in response to nicotine challenges 1,2 , and 3 , respectively. The sample exhibited mean thermic responses to nicotine of $-0.47 \pm 0.08^{\circ} \mathrm{C},-0.19 \pm$ $0.06^{\circ} \mathrm{C}$, and $-0.18 \pm 0.07^{\circ} \mathrm{C}$ at baseline and after 1 and 2 weeks of treatment with saline, respectively. These means differed $(\mathrm{df}=2 / 20$, $f=6.5, p<0.01$ ). The hypothermic response to nicotine was blunted after $1(p<0.05, t=$ $2.31, \mathrm{df}=10)$ and $2(p<0.05, t=2.48$, df $=10$ ) week of treatment relative to baseline.

\section{Discussion}

These data indicate that lithium, similar to amitriptyline, produces supersensitivity to nicotine. Those rats receiving the lower dose of $\mathrm{LiCl}$ had the higher mean plasma lithium concentration. This is partially attributable to the time at which blood was collected after the last dose. A more important factor may be biological heterogeneity. Rodents and humans vary in the plasma lithium level attained at a fixed dose. For example, some patients reach a steady-state trough plasma concentration of $1.0 \mathrm{meq} / \mathrm{liter}$ when treated with $600 \mathrm{mg}$ of lithium carbonate daily, whereas others may require $1200-1800 \mathrm{mg}$ to reach this level. Interestingly, the sample with the higher plasma lithium level became supersensitive to nicotine sooner. The development of supersensitivity to nicotine could be both timeand drug-level dependent.

Nicotine promotes the release of dopamine in the nigrostriatal and mesolimbic tracts (Andersonn et al. 1981) and triggers the release of norepinephrine in the hypothalamus (Westfall 1973). Activation of nicotinic receptors in peripheral ganglia increases the activity of tyrosine hydroxylase (Thoenen et al. 1973). Thus, the findings are consistent with the hypothesis that lithium potentiates aminergic mechanisms via effects on nicotinic mechanisms. This is consistent with the capacity of lithium to augment the efficacy of antidepressants. 
The observation that twice-daily injections of saline were associated with a blunting of the hypothermic response to saline is intriguing. This is a new finding. The routine handling of an animal and an accompanying injection are stressors (Dilsaver and Majchrzak 1989). Blunting of the hypothermic response to nicotine may be due to this stress. For our immediate purposes, it is essential to note that twice-daily injections of saline did not enhance the responsiveness of animals to nicotine. This result would have called into question our claim that twicedaily injections of $\mathrm{LiCl}$ produces supersensitivity to nicotine.

We have reported that chronic treatment with fluoxetine (Dilsaver and Davidson 1987), phenelzine (Dilsaver and Hariharan 1989), desipramine (Dilsaver and Hariharan 1988), and bright artificial light (Dilsaver and Majchrzak 1988; Dilsaver 1988) produce subsensitivity to nicotine. We established that phenelzine and desipramine do not accelerate the metabolism of nicotine. Lithium is excreted exclusively by the kidney. There is no reason to suppose that it alters the metaboloism of nicotine. There is no a priori reason to suppose that bright light alters hepatic enzymatic activity. Thus, six of the treatments studied either produced supersensitivity or subsensitivity to nicotine, and in at least four instances, pharmacokinetic effects do not appear to account for this.

The thermic responsiveness of animals of the same strain to nicotine is subject to two primary sources of variance. We previously emphasized that due to relatively great intersample variations in thermic responsiveness to agonists, experimental designs using each animal as its own control are preferred (Dilsaver and Alcssi 1988). The responsiveness of each rat to nicotine week after week is reasonably similar. This is highlighted by our finding that weekly injections of nicotine at $1.0 \mathrm{mg} / \mathrm{kg}$ does not alter the mean hypothermic response of a sample (Dilsaver et al. 1988). Finally, the source of nicotine used in the challenges may be important. Using a high-pressure liquid chromatography assay (Hariharan et al. 1987), we demonstrated that nicotine (base) degrades as it ages when routinely stored.
Lithium, similar to antidepressant treatments of several classes, alters a nicotinic mechanism. The nicotinic effects of treatments for affective disorders may be relevant to their side effect profiles or mechanisms of action. Obviously, much more serious research is needed in this area.

The authors wish to thank Mr. Duane Flemmer for his technical assistance.

\section{References}

Andersonn K, Fuxe K, Agnati LF (1981): Effects of single injections of nicotine in the ascending dopamine pathway in the rat. Evidence for increases of dopamine tumover in neostriatal and mesolimbic dopamine neurons. Acta Physiol Scand 112:345-347

Dilsaver SC (1988): Artificial light and nicotine subsensitivity. Biol Psychiatry (in press).

Dilsaver SC, Alessi NE (1988): Temperature as a dependent variable in the study of cholinergic mechanisms. Prog Neuro-Psychopharmacol Biol Psychiatry 12:1-32.

Dilsaver SC, Davidson R (1987): Fluoxetine produces subsensitivity of a nicotinic mechanism involved in the regulation of core temperature. Life Sci 41:1165-1169.

Dilsaver SC, Hariharan M (1988): Desipramine produces subsensitivity to nicotine. Psychiatry Res (in press)

Dilsaver SC, Hariharan M (1989): Nicotinic effects of antidepressants. In Gershon S, Lcrer B (cds), New Directions in Affective Disorders. New York: Springer-Verlag.

Dilsaver SC, Majchrzak M (1988): Bright artificial light produces subsensitivity to nicotine. Life Sci 42:225-230.

Dilsaver SC, Majchrzak M (1989): Effects of placebo (saline) injections on core temperature in the rat. Prog Neuro-Psychopharmacol Biol Psychiatry (in press).

Dilsaver SC, Majchrzak M, Alessi NE (1988): Chronic treatment with amitriptyline produces supersensitivity to nicotine. Biol Psychiatry 23:169-175.

Dilsaver SC, Majchrzak M, Alessi NE (1989): Telemetric measurement of core temperature in psychobiological research: Reliability and validation. Prog Neuro-Psychopharmacol Biol Psychiatry (in press). 
Hariharan M, VanNoord T, Greden J (1987): A rapid and sensitive method for simultaneous quantitation of nicotine and cotinine in biological fluids. Presented at the annual meeting of the American Clinical Chemistry Association.

Thoenen H, Otten O, Oesch E (1973): Trans-synaptic regulation of tyrosine hydroxylase. In Usdin $E$,
Snyder SH (eds), Frontiers in Catecholamine Research. New York: Pergamon Press.

Westfall TC (1973): Effect of acetylcholine on the release of $\left[{ }^{3} \mathrm{H}\right]$ norepinephrine by nicotine and potassium chloride from rat brain slices. In Usdin $E$, Snyder SH (eds), Frontiers in Catecholamine Research. New York: Pergamon Press, pp 617-668.

\title{
Plasma Norepinephrine Response to Exercise in Bulimia, Anorexia Nervosa, and Controls
}

\author{
Karl M. Pirke, Mathias Eckert, Bettina Ofers, Gerhard Goebl, \\ Barbara Spyra, Ulrich Schweiger, Reinhard J. Tuschl, and \\ Manfred M. Fichter
}

\section{Introduction}

Altered function of the sympathetic nervous system has been observed in anorexia nervosa and bulimia. The excretion of methoxy-hydroxyphenylglycol sulfate in urine (MOPEG sulfate) was found to be decreased in anorexia nervosa (Halmi et al. 1979; Abraham et al. 1981; Gerner and Gwirtsman 1981) and in bulimia (Philipp et al. 1988b). Reduced basal plasma concentrations and an impaired orthostatic response were observed in both eating disorders (Gross et al. 1979; Heufelder et al. 1985). Reduced concentrations of norepinephrine metabolites were measured in the cerebrospinal fluid of anorectic patients (Ebert et al. 1984). The increase of plasma norepinephrine after standardized test

From the Max-Planck-Institute for Psychiatry, Muenchen, and Psymchosomatische Klinik Roseneck, Prien, Federal Republic of Germany.

Address reprint requests to Dr. K. M. Pirke, Division of Psychoneurcendocrinology, Max-Planck-Institut fuer Psychiatrie, Kraepelinstr 10, D-8000 Muenchen 40, F.R.G.

Received April 1, 1988; revised September 1, 1988. meals was significantly reduced in anorectic and in normal weight bulimics (Pirke et al. 1988a). The number of alpha-2-receptors on platelets is increased (Luck et al. 1983; Heufelder et al. 1985). Norepinephrine regulates vasculatory, cardiac, ventilatory, and metabolic adaptation to exercise. Nudel et al. (1984) showed significantly lower increases in norepinephrine concentration after maximal ergometric exercise in anorectic patients than in controls. To our knowledge, no data have so far been reported for bulimic patients.

\section{Methods}

Fourteen patients with bulimia, mean age 24.0 \pm 4.0 years, 9 patients with anorexia nervosa, mean age $22.9 \pm 3.9$ years, and 11 healthy controls, mean age $23.8 \pm 3.3$ years, volunteered for the study. Patients were all female and participated in an inpatients treatment program at the Psychosomatisch Klinik Roseneck. Diagnosis was made according to the DSM-III 